
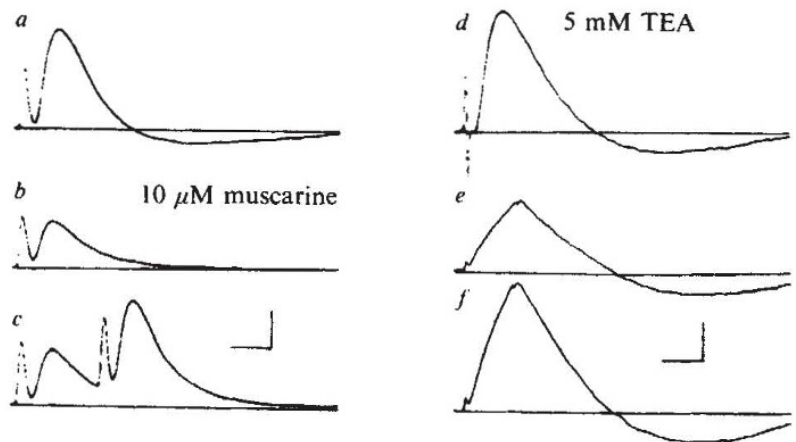

Fig. 3 Effects of muscarine and TEA on afterhyperpolarizations. $a-c$, Intracellular responses to orthodromic preganglionic input, resting $V_{\mathrm{m}}$ maintained at $-57 \mathrm{mV} ; a$, before, $b$ and $c$, after addition of muscarine $(10 \mu \mathrm{M})$. Muscarine eliminated the poste.p.s.p. hyperpolarization, even when the e.p.s.p. amplitude was restored to pre-muscarine value by repetition of input in $c$. (The smaller amplitude of e.p.s.ps in muscarine is presumably due to an additional effect of muscarinic agonists in frog ganglia, namely a presynaptic depression of the release of $\mathrm{ACh}^{7}$.) $d-f$, TEA ( $5 \mathrm{mM}$ ) already present, and resting $V_{\mathrm{m}}$ maintained at $-58 \mathrm{mV}$; afterhyperpolarizations still follow both the e.p.s.p. in $d$ and the applied depolarizing pulses in $e, f$ (constant current, $20 \mathrm{~ms}$ at $0.07 \mathrm{nA}$ for $e$ and $0.11 \mathrm{nA}$ for $f$ ). That TEA was having its expected effect on other $\mathrm{K}^{+}$channels was evident in a prolongation of the action potential (not shown). Calibration: $4 \mathrm{mV}$ and $20 \mathrm{~ms}$ for $a-c ; 1 \mathrm{mV}$ and $20 \mathrm{~ms}$ for $d-f$.

The above evidence supports the proposal that the poste.p.s.p. hyperpolarization is a voltage-activated response; it is induced when the e.p.s.p. sufficiently depolarizes the membrane, and it can thus 'contaminate' the e.p.s.p. response. The dependence of post-e.p.s.p. hyperpolarization on the amplitude of the e.p.s.p. further indicates that it is a true afterhyperpolarization rather than a separate, transmitter-induced p.s.p.; the relationship was seen whether the amplitude of the e.p.s.p. was varied by repetition of input (as in Fig. 1) or by strength of curarization. (When e.p.s.ps were more strongly suppressed by greater curarization, post-e.p.s.p. hyperpolarizations were also smaller or absent.) That the voltage-activated post-e.p.s.p. hyperpolarization is a function of the opening of $\mathbf{M}$ channels by the e.p.s.p. is indicated by (1) the similarity of the range of $V_{m}$ in which both appear, and (2) blockade of both by muscarine, but not by TEA. The more than linear increase in post-e.p.s.p. hyperpolarization when the amplitude of the e.p.s.p. was increased (Fig. 1) would be expected, as $\mathbf{M}$ channel conductances do show progressively greater increases with increasing depolarization of $V_{\mathrm{m}}$ in the range between $-60 \mathrm{mV}$ and $-40 \mathrm{mV}$ (ref. 1). Post-e.p.s.p. hyperpolarizations are of briefer duration and have smaller time constants than do those obtained for M-channel closure when a depolarized $V_{\mathrm{m}}$ is changed suddenly to a hyperpolarized holding level ${ }^{1}$, but this is also readily explainable: $M$ channels that are increasingly opened as e.p.s.p. depolarization rises, would begin to close progressively during the slow, descending, repolarizing limb of the e.p.s.p. Thus, the duration and time constant solely of the post-e.p.s.p. hyperpolarization phase that survives after the end of e.p.s.p. depolarization would not reflect the total time of the whole process.

As post-e.p.s.p. hyperpolarization in fact appears only in a limited range of $V_{\mathrm{m}}$, its presence or absence can be used to indicate limits for values of the resting $V_{\mathrm{m}}$ of uninjured neurones, without directly measuring $V_{\mathrm{m}}$ using an intracellular microelectrode.

In 20 preparations, the extracellular (total population) e.p.s.p. response of intact frog ganglia ${ }^{5}$ was never followed by a post-e.p.s.p. hyperpolarization, whether elicited by a single stimulus or a train of maximal $\mathrm{B}$ or $\mathrm{B}$ plus $\mathrm{C}$ preganglionic volleys, when the true slow i.p.s.p. had previously been eliminated by atropine. On the other hand, during application of limited depolarizing current, passed via the surface recording electrodes, the extracellular e.p.s.p. did exhibit a post-e.p.s.p. hyperpolarization in 5 of 11 intact ganglia tested. We conclude that the resting $V_{\mathrm{m}}$ of these intact sympathetic neurones is at least equal or negative to $-65 \mathrm{mV}$. For neurones impaled by a microelectrode, mean resting $V_{\mathrm{m}} \mathrm{s}$ of $-50 \mathrm{mV}$ (ref. 3), $-54 \mathrm{mV}$ (ref. 2) and -65 (range -55 to -75$)^{6} \mathrm{mV}$ have been reported.

This research was supported in part by USPHS research grant NS-00884 from the National Institute of Neurological and Communicative Disorders and Stroke.

Received 4 May; accepted 9 June 1983.

1. Brown, D. A. \& Adams, P. R. Nature 283, 673-676 (1980).

2. Blackman, J. G., Ginsborg, B. L. \& Ray, C. J. Physiol., Lond. 167, 355-373 (1963).

3. Tosaka, T., Chichibu, S. \& Libet, B. J. Neurophysiol. 31, 396-409 (1968).

. Coombs, J. S., Eccles, J. C. \& Fatt, P. J. Physiol., Lond. 130, 374-395 (1955).

Libet, B., Chichibu, S. \& Tosaka, T. J. Neurophysiol. 31, 383-395 (1968).

Nishi, S. \& Koketsu, K. J cell comp. Physiol 55, 15-30 (1960).

Koketsu, K. \& Yamada, M. Br. J Pharmac. 77, 75-82 (1982).

\section{Adoptive transfer of EAE-like lesions from rats with coronavirus-induced demyelinating encephalomyelitis}

\section{Rihito Watanabe, Helmut Wege \& Volker ter Meulen}

Institute of Virology and Immunobiology, University of Würzburg, Versbacher Str. 7, D-8700 Würzburg, FRG

Viruses have been found to induce inflammatory demyelinating lesions in central nervous system (CNS) tissue of both animal and man, either by natural infections or after vaccination ${ }^{1,2}$. At least two different pathogenic mechanisms have been proposed for these changes, a cytopathic viral infection of oligodendroglia cells with subsequent cell death, and a host immune reaction against virus and brain antigens. We now report the occurrence of cell-mediated immune reactions against basic myelin proteins in the course of coronavirus infections in Lewis rats. Infection of rats with the murine coronavirus JHM leads to demyelinating encephalomyelitis developing several weeks to months postinfection $^{3-7}$. Lymphocytes from these diseased Lewis rats can be restimulated with basic myelin protein (BMP) and adoptive transfer of these cells leads to lesions resembling those of experimental allergic encephalomyelitis (EAE) in recipients, which can be accompanied by a mild clinical disease. This model demonstrates that a virus infection in CNS tissue is capable of initiating an autoimmune response which may be of pathogenic importance.

Intracerebral inoculation of Lewis rats at the age of 4-5 weeks with wild-type coronavirus JHM $\left(1 \times 10^{4}\right.$ plaque-forming units (PFU) per rat) was followed after an incubation period of several weeks by the development of a subacute demyelinating encephalomyelitis (SDE). Diseased animals revealed unsteadiness, ataxic gait, abnormal posturing of the limbs, hindleg paralysis or a complete paraplegia. Most of these animals recovered from SDE and only some rats died within a few days after onset of disease. The neuropathological changes consisted of demyelinated plaques which were distributed in thalamus, brain stem, cerebellum and spinal cord and were located predominantly in the white matter. Figure $1 a$ shows such a plaque. Within the plaques, cell infiltrations which consisted mainly of macrophages (Fig. $1 b, c$ ), were found. As documented by Fig. 1c, axons were well preserved within the demyelinated area. Furthermore, perivascular cuffings were frequently observed in diseased rats (Fig. 1a). These cuffings were mainly found in the brain stem and spinal cord and were restricted to the space around the blood vessel (VirchowRobins space, Fig. 1d). The destruction of myelin around these infiltrations was usually not prominent. Conventional virus isolation procedures permitted isolation of infectious coronavirus 
Table 1 Proliferative response of lymphocytes cultured in presence of antigens

\begin{tabular}{|c|c|c|c|c|c|c|c|c|}
\hline \multirow{2}{*}{$\begin{array}{l}\text { Group } \\
\text { of rats }\end{array}$} & \multirow{2}{*}{$\begin{array}{l}\text { No. of } \\
\text { animal }\end{array}$} & \multirow{2}{*}{$\begin{array}{l}\text { Control } \\
\text { medium } \\
\text { (c.p.m.) }\end{array}$} & \multicolumn{2}{|c|}{ BMP } & \multicolumn{2}{|c|}{$\begin{array}{l}\text { Antigens } \\
\text { JHM virus }\end{array}$} & \multicolumn{2}{|l|}{ Histone } \\
\hline & & & (c.p.m.) & SI & (c.p.m.) & SI & (c.p.m.) & SI \\
\hline SDE & $\begin{array}{l}1 \\
2 \\
3 \\
4 \\
5\end{array}$ & $\begin{array}{l}2,454 \pm 685 \\
5,913 \pm 539 \\
1,638 \pm 84 \\
3,866 \pm 295 \\
2,650 \pm 96\end{array}$ & $\begin{array}{c}20,477 \pm 933 \\
39,815 \pm 4,118 \\
4,366 \pm 202 \\
4,530 \pm 666 \\
6,244 \pm 680\end{array}$ & $\begin{array}{l}\times 8.3 \\
\times 6.7 \\
\times 2.7 \\
\times 1.2 \\
\times 2.4\end{array}$ & $\begin{array}{c}38,039 \pm 1,746 \\
45,521 \pm 8,477 \\
4,738 \pm 602 \\
14,191 \pm 968 \\
9,045 \pm 767\end{array}$ & $\begin{array}{l}\times 15.5 \\
\times 7.7 \\
\times 2.8 \\
\times 3.7 \\
\times 3.4\end{array}$ & $\begin{array}{l}2,944 \pm 139 \\
5,321 \pm 482 \\
1,801 \pm 203 \\
3,692 \pm 464 \\
2,411 \pm 284\end{array}$ & $\begin{array}{l}\times 1.2 \\
\times 0.9 \\
\times 1.1 \\
\times 1.0 \\
\times 0.9\end{array}$ \\
\hline Average & & $3,304 \pm 1,486$ & $15,086 \pm 13,748$ & $\times 4.3 \pm 2.7$ & $22,306 \pm 16,351$ & $\times 6.6 \pm 4.8$ & $3,233 \pm 1,214$ & $\times 1.0 \pm 0.1$ \\
\hline Uninfected & $\begin{array}{l}1 \\
2 \\
3 \\
4 \\
5\end{array}$ & $\begin{array}{l}3,148 \pm 156 \\
2,187 \pm 126 \\
2,480 \pm 84 \\
4,452 \pm 267 \\
2,156 \pm 80\end{array}$ & $\begin{array}{l}3,396 \pm 123 \\
1,899 \pm 510 \\
2,340 \pm 360 \\
3,481 \pm 215 \\
1,841 \pm 55\end{array}$ & $\begin{array}{l}\times 1.1 \\
\times 0.9 \\
\times 0.9 \\
\times 0.8 \\
\times 0.9\end{array}$ & $\begin{array}{l}2,833 \pm 301 \\
2,361 \pm 174 \\
1,984 \pm 223 \\
4,814 \pm 215 \\
2,324 \pm 118\end{array}$ & $\begin{array}{l}\times 0.9 \\
\times 1.1 \\
\times 0.8 \\
\times 1.1 \\
\times 1.1\end{array}$ & $\begin{array}{l}2,575 \pm 74 \\
1,740 \pm 528 \\
2,532 \pm 776 \\
2,671 \pm 253 \\
1,940 \pm 147\end{array}$ & $\begin{array}{l}\times 0.8 \\
\times 0.8 \\
\times 1.0 \\
\times 0.6 \\
\times 0.9\end{array}$ \\
\hline Average & & $2,884 \pm 861$ & $2,591 \pm 713$ & $\times 0.9 \pm 0.1$ & $2,863 \pm 1,012$ & $\times 1.0 \pm 0.1$ & $2,291 \pm 376$ & $\times 0.8 \pm 0.1$ \\
\hline EAE & $\begin{array}{l}1 \\
2 \\
3 \\
4\end{array}$ & $\begin{array}{l}2,086 \pm 148 \\
3,461 \pm 34 \\
2,532 \pm 260 \\
2,679 \pm 61\end{array}$ & $\begin{array}{c}5,038 \pm 748 \\
12,327 \pm 1,042 \\
5,214 \pm 86 \\
9,405 \pm 284\end{array}$ & $\begin{array}{l}\times 2.4 \\
\times 3.6 \\
\times 2.1 \\
\times 3.5\end{array}$ & $\begin{array}{l}2,470 \pm 112 \\
1,409 \pm 65 \\
2,310 \pm 922 \\
2,961 \pm 46\end{array}$ & $\begin{array}{l}\times 1.2 \\
\times 0.4 \\
\times 0.9 \\
\times 1.1\end{array}$ & $\begin{array}{c}\text { ND } \\
\text { ND } \\
2,713 \pm 765 \\
\text { ND }\end{array}$ & $\times 1.1$ \\
\hline Average & & $2,689 \pm 496$ & $7,997 \pm 3,050$ & $\times 2.9 \pm 0.6$ & $2,287 \pm 561$ & $\times 0.9 \pm 0.3$ & & \\
\hline
\end{tabular}

Values summarize the counts per min (c.p.m.) and the stimulation indices (SI) obtained from five SDE rats, five uninfected animals and four rats with EAE. Lymphoid cells from SDE rats were taken 2 days after onset of disease (2-3 weeks after infection). EAE animals were killed 2 weeks after BMP immunization. Immunization was carried out according to Richert et al. ${ }^{8}$. From individual animals cells from spleen, thymus and peripheral blood were pooled. As lymphocytes from popliteal lymph nodes could only be obtained from EAE animals, this cell population was not included in the comparative study. Cells were cultured in 96-well microplates with RPMI 1640 supplemented by heat-inactivated fetal calf serum, 2-mercaptoethanol, antibiotics and sodium carbonate, at a cell density of $1 \times 10^{6}$ per well for $72 \mathrm{~h}$, with the addition of feeder cells $\left(1 \times 10^{5}\right.$ mitomycin C-treated spleen cells). Before incubation, $1 \mu \mathrm{g}$ per well of the required antigen was added. $1 \mu \mathrm{Ci}{ }^{3} \mathrm{H}$-thymidine was added to each well $24 \mathrm{~h}$ before collection and the stimulation indices were calculated and compared with those of cultures without antigen ${ }^{8}$. As a source of BMP, guinea pig spinal cords were extracted according to the method described previously ${ }^{18}$ to obtain a potent antigen for the specific restimulation of sensitized lymphocytes. To exclude the presence of JHM virus in lymphocytes from SDE animals, lymphoid cell aliquots of the cell preparations used for stimulation experiments were processed for virus isolation before and after stimulation with BMP or concanavalin A. Cells were distributed on monolayers of L cells in Costar plates, or homogenized before adsorption to $\mathrm{L}$ cells and incubated at $37^{\circ} \mathrm{C}$ for 3 days. Infectious virus was not isolatable even after two blind passages. In addition, lymphoid cells from healthy rats ( 2 months old) were exposed to $\mathrm{JHM}$ virus at different multiplicities for $1 \mathrm{~h}$ at $37^{\circ} \mathrm{C}$ and further cultured after washing. Again, no infection of lymphocytes was noted and no JHM antigen was detectable in either of the cell preparations, suggesting that rat lymphoid cells do not support replication of JHM virus. ND, not done.

Fig. $1 a-d$, Lewis rat with onset of SDE 20 days post-infection. $a$, Demyelinated plaques in cervical spinal cord in antero-lateral white matter. Note perivascular cell infiltration (arrow). Double-staining with haematoxylin-eosin and Luxol fast blue. $\times 51 . b$, Higher magnification $(\times 248)$ of the same plaque. Myelin is almost completely absent and infiltrated macrophages contain myelin debris. $c, 1-\mu \mathrm{m}$ section from same level as $a$ and $b$. Well-preserved demyelinated axons (arrowheads) are seen. Macrophages contain myelin debris (arrow). Toluidine blue stain. $\times 443$. $d$, Perivascular cell infiltration in the spinal cord of the same rat. Toluidine blue staining. $\times 359$. $e$, Transferred perivascular EAE-like lesions in the posterior column and meninx of the spinal cord. The animal shown in $a-d$ was perfused with glutaraldehydeparaformaldehyde after lympho-
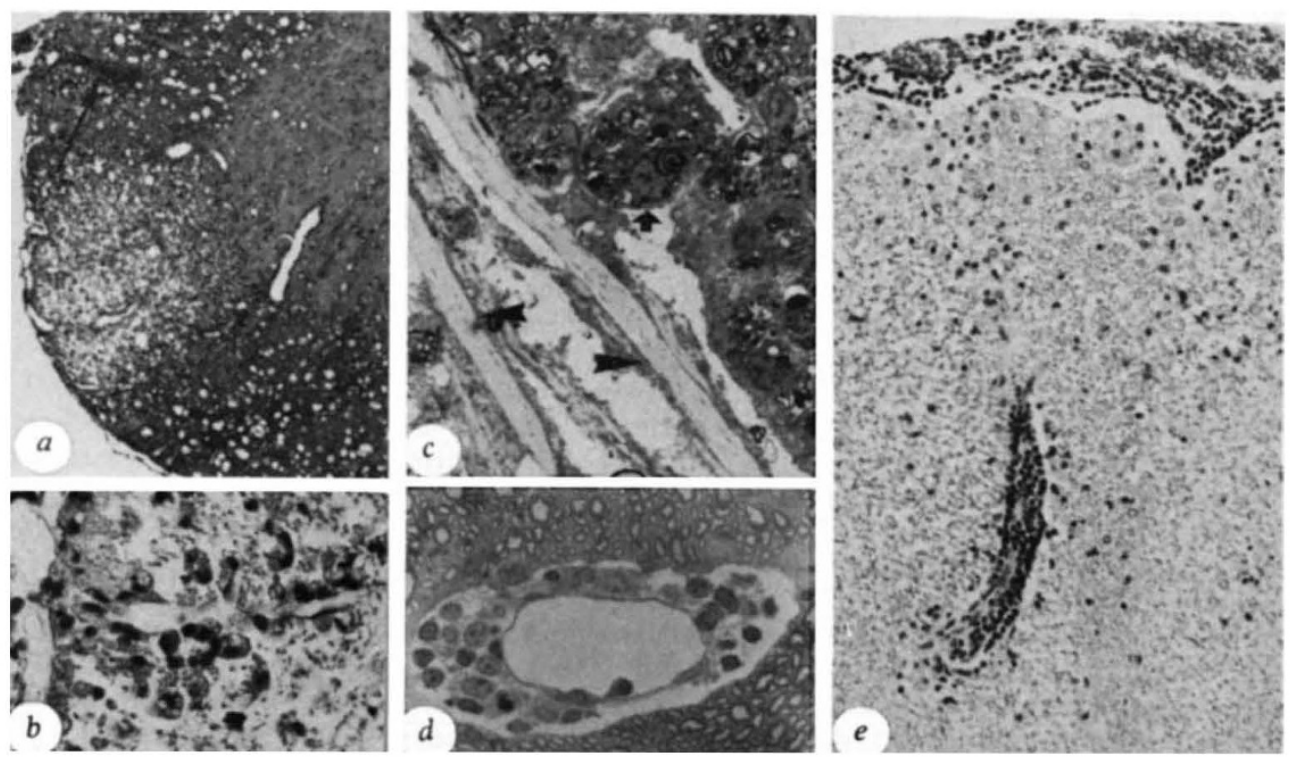

cytes had been taken for stimulation assays. The tissue specimens were embedded in paraffin $(a, b)$ or in epon after fixation in osmium tetroxide $(c, d)$ for $1-\mu \mathrm{m}$ sections. The rat shown in $e$ received $1 \times 10^{8}$ lymphocytes from an animal with SDE after in vitro culture with BMP. Paraffin-embedded section, haematoxylin-eosin staining. $\times 125$.

from brain or spinal cord at the time of clinical disease and up to 10-12 days after inoculation. Viral antigen was primarily detectable by immunohistological procedures in glia cells in the neighbourhood of demyelinating plaques and not in cells constituting perivascular cuffings.

The marked infiltration of lymphocytes in the affected brain areas (Fig. 1d) to some extent resembles changes seen in EAE.
This observation prompted us to perform immunological studies to evaluate the state of lymphocyte sensitization against BMP. Lymphocytes from individual Lewis rats with SDE were collected from spleen, thymus and peripheral blood 2 days after onset of disease and cultured for 3 days in the presence of BMP. As shown in Table 1 , the lymphocytes of most rats were sensitized against BMP as measured by ${ }^{3} \mathrm{H}$-thymidine 
Table 2 Adoptive transfer of cultured lympoid cells to rats

Cells transferred

\section{Donor}

SDE rats

Normal rats

Normal rats
Antigen stimulation

\section{BMP for 3 days}

None for 3 days

BMP for 3 days

BMP for 3 days + JHM virus
EAE-like lesions in recipients

$$
\begin{gathered}
\text { Clinical } \\
6 / 26 \\
0 / 5 \\
0 / 8 \\
0 / 5 \\
0 / 4 \\
0 / 6
\end{gathered}
$$

Histological

$13 / 26$

$0 / 5$

$0 / 8$

$0 / 5$

$0 / 4$

$0 / 6$
Detection of JHM virus in brain or spinal cord in recipients

$\begin{array}{cc}\text { Infectious virus } & \text { Antigen } \\ 0 / 12 & 0 / 12 \\ 0 / 3 & 0 / 3 \\ 0 / 2 & 0 / 2 \\ 0 / 5 & 0 / 5 \\ 0 / 4 & 0 / 4\end{array}$

$0 / 60 / 6$

Intravenous inoculati
into normal rats

Spleen, thymus and peripheral blood cells from SDE rats were taken within 2 days after onset of clinical symptoms and pooled to obtain a maximum cell yield. Lymphoid cells at a density of $1 \times 10^{7}$ per ml were incubated with or without $10 \mu \mathrm{g} \mathrm{ml}^{-1} \mathrm{BMP}$ extracted from guinea pig spinal cord. After $72 \mathrm{~h}$ the cells were collected and washed four times in Hank's balanced salt solution. $1 \times 10^{8}$ viable cells were transferred i.v. to normal syngeneic rats. Recipients without clinical signs were killed on day 10 after cell transfer ${ }^{8}$. For virus isolation attempts the left brain hemisphere and cervical part of the spinal cord from control rats were homogenized and inoculated on monolayers of $L$ cells on Costar plates according to the method described previously ${ }^{7}$. Part of the right brain hemisphere and the spinal cord were processed for immunohistology with the peroxidase-antiperoxidase method. As additional control experiments, BMP-restimulated and unstimulated lymphoid cells from normal rats ( 2 months old) were exposed to JHM virus at multiplicities of $0.1-1$, and transferred i.v. to rats. Each rat received $1-3 \times 10^{8}$ viable cells. Also, JHM virus $\left(10^{6}-10^{8}\right.$ PFU per animal) was injected i.v. into rats ( 2 months of age). Both experiments were terminated 10 days after cell transfer or virus inoculation.

incorporation. The stimulation indices observed were similar to values for lymphocytes from rats with EAE and greater than the values obtained using cells from uninfected animals. Lymphocytes from SDE animals were also easily restimulated by purified inactivated coronavirus particles. Interestingly, neither infectious JHM virus not JHM antigens were detectable in lymphoid cells from SDE rats before or after stimulation with either specific antigen or mitogen.

To discover whether lymphocytes from rats with SDE could induce histopathological changes in the CNS, cells restimulated with BMP were transferred into healthy recipients by the intravenous (i.v.) route ${ }^{8}$. The results of these experiments are summarized in Table 2 . After transfer of $1 \times 10^{8}$ lymphocytes per animal, 6 of 26 animals showed slight clinical signs such as weight loss, abnormal sensitivity to touch or slight ataxic gait. These clinical signs were seen within 5 days of transfer. Perivascular mononuclear cell infiltration was observed histologically in 13 animals. An example of such an infiltration is shown in Fig. 1e. This type of lesion was similar to $\mathrm{EAE}$, or passively transferred $\mathrm{EAE}^{8}$. The infiltrations were predominantly found in the dorsal area of the spinal cord white matter. This location of lesions could explain the low frequency of clinical symptoms. Additional perivascular cuffs were detected in the pons, cerebellar white matter and thalamus. Small scattered cell infiltrations were visible near the perivascular cuffs but no extended demyelination was detectable. No lesions were observed if lymphocytes from uninfected rats were transferred after culture in presence of BMP, or after exposure to infectious JHM virus. It is unlikely that these lesions are caused by transfer of coronavirus because we were unable either to reisolate infectious virus from lymphocytes from rats with SDE, or to detect infectious JHM virus or antigens in brain areas with lesions from animals which received restimulated lymphocytes. Furthermore, i.v. inoculation of normal rats with high doses of virus or virus-lymphocyte mixtures did not lead to CNS lesions.

The destruction of oligodendroglia cells by viruses has been shown to have a role in the development of demyelination in experimental models. However, only circumstantial evidence exists that a virus infection initiates an immune response which contributes to brain injury as suggested in infections with canine distemper, Theiler, visna or vaccinia viruses ${ }^{9-14}$. The data presented here indicate that in the course of coronavirus JHM infection of Lewis rats, lymphocytes were sensitized against BMP. Adoptive transfer of these lymphocytes after in vitro restimulation with BMP was followed by EAE-like lesions in recipient Lewis rats. Coronavirus replication in the CNS can therefore produce a similar effect to Freund's complete adjuvant plus BMP in EAE. It will be of great importance to understand how a virus infection triggers an immune response against neuroantigens. There are several possibilities. First, it is conceivable that JHM virus structural proteins which are formed in CNS cells contain antigenic sites which cross-react with myelin. An immune response against these proteins would therefore be directed against both virus proteins and myelin. Some evidence for such a mechanism has been obtained for measles virus infection in subacute sclerosing panencephalitis, in which antibodies to measles virus reacted with $\mathrm{BMP}^{15}$. However, cell-mediated immune reactions were not measured. Second, the infection of oligodendroglia cells by JHM virus may lead to membrane changes resulting in the development of immunogenic structures also recognized on uninfected cells thus inducing an autoimmune process. So far, this mechanism has been suggested for viruses which bud from cell membranes ${ }^{16}$. How coronaviruses are released from infected cells is unknown, but it is possible to detect viral antigens on the cell membrane. The role of these membrane-associated viral antigens in assembly or release is unknown. Third, coronavirus infection of oligodendroglia cells could lead to the release of myelin material which is immunogenic. The resulting series of events would then follow those of EAE. There has been some evidence that a persistent measles virus infection in hamsters supports the development of EAE when such animals are challenged with BMP in combination with Freund's complete adjuvants ${ }^{17}$. Whether the measles infection renders the CNS more vulnerable to immunological injury or immunopotentiates a cell-mediated immune response to myelin has not yet been elucidated.

None of these different mechanisms has been proven for any of the various models established for virus-induced demyelination, but coronavirus JHM infection in Lewis rats may now permit such an analysis. In addition, this model may provide significant information in the study of chronic inflammatory CNS diseases of man such as multiple sclerosis.

We thank Renate Abt, Margarete Sturm and Hanna Wege for technical assistance, and Helga Kriesinger for preparing the manuscript. The work was supported by Deutsche Forschungsgemeinschaft and Humboldt-Stif tung.

\section{Received 31 January; accepted 11 July 1983}

1. Weiner, L. P., Johnson, R. T. \& Herndon, R. M. New Engl. J. Med. 288, 1103-1110 (1973). 2. ter Meulen, V. \& Hall, W. W. J. gen. Virol. 41, 1-25 (1978).

3. Nagashima, K., Wege, H., Meyermann, R. \& ter Meulen, V. Acta neuropath. 44, 63-70 (1978).

4. Nagashima, K., Wege, H., Meyermann, R. \& ter Meulen, V. Acta neuropath. 45, 205-213 (1979). 
5. Sörensen, O., Percy, D. \& Dales, S. Archs Neurol. 37, 478-484 (1980).

6. Sörensen, O. Dugre, R., Percy, D. \& Dales, S. Infect. Immunity 37, 1248-1260 (1982)

7. Wege, H., Koga, M., Watanabe, R., Nagashima, K. \& ter Meulen, V. Infect. Immunity 39, 1316-1324 (1983).

8. Richert, J. R., Driscoll, B. F., Kies, M. W. \& Alvord, E. C. J. Immun. 122, 494-496 (1979).

9. Vandevelde, M. et al. Acta neuropath. 56, 285-293 (1982).

10. Lipton, H. L. \& Dal Canto, M. C. Science 192, 62-64 (1976)

11. Lipton. H. L. \& Dal Canto, M. J. neurol. Sci. 42, 391-405 (1979).

12. Panitch, H., Petursson, G., Georgsson, G., Palsson, P. \& Nathanson, N. Lab. Invest. 35, 452-460 (1976).

13. Tschannen, R., Steck, A. J. \& Schäfer, R. Neurosci. Lett. 15, 295-300 (1979)

14. Steck, A. J., Tschannen, R. \& Schäfer, R. J. Neuroimmun, 1, 117-124 (1981).

15. Panitch, S. H., Swoveland, P. \& Johnson, K. P. Neurology 29, 548-549 (1979).

16. Drzeniek, R. \& Rott, R. Int. Archs Allergy 36, 146-152 (1969).

17. Massanari, R. M., Paterson, P. Y. \& Lipton, H. L. J. infect. Dis. 139, 297-303 (1979)

18. Deibler, G. E., Martenson, R. E. \& Kies, M. W. Prep. Biochem. 2, 139-165 (1972).

\section{Defective translation of measles virus matrix protein in a subacute sclerosing panencephalitis cell line}

\author{
Michael J. Carter, Margaret M. Willcocks \\ \& Volker ter Meulen
}

Institut für Virologie und Immunobiologie, Universität Würzburg, D-8700 Würzburg, FRG

Subacute sclerosing panencephalitis (SSPE) is a slowly progressing fatal human disease of the central nervous system (CNS) that is associated with measles virus persistence. Virus nucleocapsids are present in the brain ${ }^{1,2}$ and the patient is in a state of hyperimmunization towards this agent. However, although all other structural polypeptides are recognized by the immune system, there is a markedly decreased antibody response towards virus matrix or membrane protein ${ }^{3,4}$. Matrix protein has not been detected in brain cells ${ }^{5}$ and infectious virus is not present. The absence of this virus structural polypeptide is thought to account for the apparent restriction in virus maturation both in vivo and in vitro. SSPE viruses can only rarely be rescued from brain tissue by co-cultivation or cell fusion techniques using tissue culture cell lines susceptible to measles virus infection ${ }^{6}$. Often this procedure fails to yield a lytic budding virus but produces instead a carrier cell line in which the agent is cell associated. These lines (known as SSPE cell lines) also do not contain matrix protein ${ }^{7,8}$. However, the reason for this deficiency is unknown. We have therefore now examined an SSPE cell line which does not yield infectious virus in order to define this process further. We found that although messenger RNA for membrane protein was present, it was unable to form normal matrix protein in translation reactions.

In our laboratory we have examined an SSPE cell line (N-1) obtained by co-cultivation of SSPE brain material with Vero cells 9 . This cell line shows slowly spreading areas of cell fusion, but does not release infectious virus, although particles can be obtained by procedures which favour cell fragmentation ${ }^{10,11}$. During ordinary cell culture procedures, or in co-cultivation and cell fusion experiments, we have never detected release of infectious virus. Results of electron microscopic examination of the $\mathrm{N}-1$ cells are consistent with a defect in virus maturation, and the virus nucleocapsids are randomly distributed throughout the cytoplasm ${ }^{12}$. These cells are thus a good model for the situation observed in CNS cells from SSPE patients.

Measles virus proteins can be detected in infected cells by immunoprecipitation and comprise: the large protein (L), haemagglutinin $(\mathrm{H})$, phosphoprotein $(\mathrm{P})$, nucleocapsid $(\mathrm{N})$ and its degradation product (NC), the fusion protein, both uncleaved $\left(F_{0}\right)$ and cleaved $\left(F_{1}\right)$, and the matrix protein $(M)$. The $P$ protein is poorly recognized by the serum used in this work, but the small band $(\mathrm{X})$ detected in infected cells and known to be related $^{13}$ to $\mathrm{P}$ was precipitated from both cell lysates and in vitro translation products. We confirmed that this protein is unrelated to matrix protein using the technique of Cleveland mapping ${ }^{25}$. All of these proteins were detected in lysates of

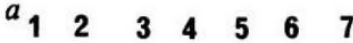

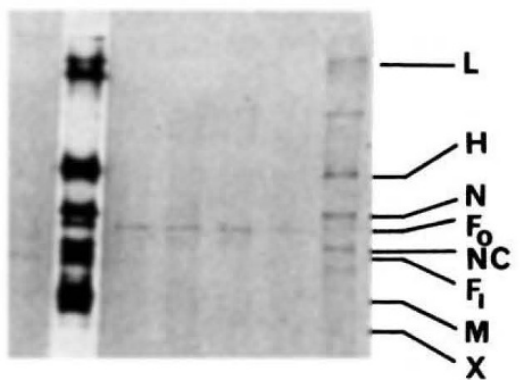

$\begin{array}{llllll}b_{1} & 2 & 3 & 4 & 5 & 6\end{array}$

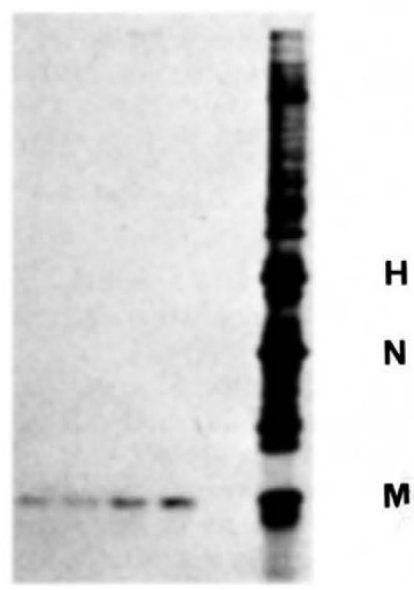

Fig. $1 a$, Immunoprecipitation of measles-specific proteins from $\mathrm{N}-1$ cells. Cells were labelled with ${ }^{35} \mathrm{~S}$-methionine $(1,200-$ $1,400 \mathrm{Ci} \mathrm{mMol}^{-1}$, Amersham Buchler) for $2 \mathrm{~h}$ when the cytopathic effect was maximal. Lysates were prepared and analysed by immunoprecipitation and electrophoresis on a $10 \%$ SDS-polyacrylamide gel as described elsewhere ${ }^{3}$. Gels were fluorographed and exposed to Fuji X-ray film. Samples were precipitated with: tracks $1,2,7$, rabbit hyperimmune anti-measles serum; track 3 , control ascites fluid; tracks 4-6, ascites fluids containing monoclonal antibodies directed against Edmonston measles virus matrix protein. Track 1, lysate prepared from uninfected Vero cells; track 2, lysate prepared from Edmonston virus-infected Vero cells; tracks 3-7, lysates prepared from $\mathrm{N}-1$ cells. $b$, Specificity of monoclonal antibodies. Lysates were prepared from Edmonston measles virus-infected Vero cells and immunoprecipitated with: tracks $1-4$, anti-measles virus matrix protein monoclonal antibodies; track 5, monoclonal antibody raised against coronavirus; track 6 , total cell lysate, without immunoprecipitation.

Edmonston measles virus-infected Vero cells. All except matrix protein could be demonstrated in lysates prepared from $\mathrm{N}-1$ cells (Fig. 1a). Matrix protein was also not detected by immunofluorescence or radioimmunoassay using four monoclonal M-specific antibodies (Fig. $1 b$ ) which also cross-react with the non-defective SSPE virus $\mathrm{Lec}^{14}$. However, the levels of virus protein expression were low in these cell populations, as only a small percentage of cells $(10-20 \%)$ were infected. Analysis by radioimmunoprecipitation was complicated by background host-cell proteins (Fig. 1, track 1) and nucleocapsid degradation products which migrated in the matrix protein region (38,000 molecular weight). The long exposures required to search for trace amounts of matrix protein were found unsatisfactory, and it was therefore necessary to analyse protein production in vitro. This results in a decreased background in immunoprecipitation ${ }^{14}$. Matrix protein production could be prevented by a defect in either transcription or translation, and it is known that this inhibition is to some extent host-controlled, as cell fusion experiments have occasionally resulted in the rescue of infectious virus ${ }^{6}$. Therefore, in vitro translation was 